\title{
Mathematical Modelling of Pollutants' Dispersion in Soil I. Case Study of Copper Dispersion
}

\author{
V. Viman, L. Mihaly Cozmuta, A. Mihaly Cozmuta, Gh. Vatca, C. Varga and G. Oprea \\ North University of Baia Mare, Chemistry-Biology Department, Victoriei Str. 76, Baia Mare, Romania
}

\begin{abstract}
The study presents a mathematical modelling of copper dispersion in soil. The samples have been collected from the same points of the sampling network, from surface and depth in 2001 and only to surface in 2002 and analyzed using the ICP-AES method. The extrapolation of the experimental results led to the dispersion curves of the copper concentrations both at surface and depth. Based on these, the appreciation of the most polluted areas and theirs migration related to characteristics of the environment can be observed.
\end{abstract}

Key words: Soil pollution with heavy metals, dispersion curves, ICP-AES

\section{INTRODUCTION}

The study was developed in a strongly polluted area with heavy metals. It is located nearest to the sedimentation ponds where are collected the wastewaters coming from industrial plants of the Baia Mare town.

The oldest pond in the area (Fig. 1) is about 20 years in preservation. The area where the wastewaters used to be discharged was covered in soil and rehabilitated by planting the bushes.

Remin Sedimentation Pond (Fig. 1), called "the old pond", built in 1977 , covers $1,050,000 \mathrm{~m}^{2}$, is $30 \mathrm{~m}$ deep (190 survey mark) with an embankment of $18-20^{\circ}$. From the pipes, the wastewaters collected from industrial plants of Baia Mare, are mechanical purified in the hydrociclones located on the wall of the pond. The resulted liquid phase is spilled in the pond and the solid waste is deposited on the wall with the roll of rising and reinforcing. The built-up rate of $2 \mathrm{~m} / \mathrm{annum}$ has allowed over $150,000,000 \mathrm{~m}^{3}$ of tailings to accumulate in the pond. The geological study ${ }^{[1]}$ indicates that the base of the pond is made by clay covered by the permeable layers of rocks and sand. Also, the fine granullometry of the wall make it easy transported by the winds. There were a few attempts to consolidate the pond by planting trees. The best accommodation is noticed for acacia.

The newest pond in the area is Transgold Sedimentation Pond (Fig. 1) where are discharged the wastewaters from extraction of gold and silver using cyanidation method. It is about $3,8 \mathrm{Km}$ long and spread on $70,000 \mathrm{~m}^{2}$. Because of the high content of cyanide in discharged waters, a plastic layer covers the bottom of the pond to avoid the dispersion by capillarity. Despite of it, the pollution of the environment was recorded. The major accident occurred in December 1999January 2000, when due to construction problems and increased of rain, the NW wall (Fig. 1) of the pond collapsed and over $100,000 \mathrm{~m}^{3}$ of wastewaters were spilled and dispersed in adjacent fields and rivers ${ }^{[2]}$. After the accident, about $4 \mathrm{~m}$ wide and $2 \mathrm{~m}$ depth channel around the pond and a "protection area" at the NW side (Fig. 1) was built to collect the wastewaters accidentally discharged.

\section{MATERIALS AND METHODS}

The study which covers two consecutive years, 2001 and 2002, presents the dispersion in soil of copper ions from the wastewaters of Transgold sedimentation pond, accidentally spilled in January 2001.

In the first year, five directions from A to $\mathrm{E}$ (Fig. 1) around to the pond and $200 \mathrm{~m}$ distance one to other sampling points along of each direction were established. In addition, other 12th individual points inside of the protection area (Fig. 1) were selected to provide a high accuracy of the study. The whole sampling network contained $32^{\text {nd }}$ sampling points. Two soil samples have been collected from each point, one from the surface $(5 \mathrm{~cm})$ after removing of the vegetation layer and the other in depth $(30 \mathrm{~cm})$, each of them weighing about $1 \mathrm{~kg}$. For each point, the coordinates were settled using a GPS-Magellan 310 device. In the second year, the soil samples were collected from the same points of the first year, but only on surface $(5 \mathrm{~cm})$.

The samples were stored in plastic bags, marked and prepared for analysis. After air-dried at room temperature, they were grinded in agate mortars, sieved at -500 microns and dissolved as follows ${ }^{[3]}: 10 \mathrm{~mL}$ of 1:1 (v/v) $\mathrm{HCl}$ was added to $0.2 \mathrm{~g}$ soil in a $150 \mathrm{~mL}$ beaker and the sample heated to near dryness. After cooling, $10 \mathrm{~mL}$ of $3: 1(\mathrm{v} / \mathrm{v}) \mathrm{HNO}_{3}+\mathrm{HCl}$ lunge mixture, was added and again the acid was evaporated to near dryness. The residue was dissolved in $25 \mathrm{~mL} \mathrm{HCl} \mathrm{1:4}$ 
$(\mathrm{v} / \mathrm{v})$ and heated for approximatively 15 minutes in open air. The sample was then transferred into a 100 $\mathrm{mL}$ volumetric flask and diluted to volume with distilled water. The sample was filtered to remove suspended particulate matter before analysis. The copper amount was determined using ICP-AES method at specific wave lengths $324.7 \mathrm{~nm}$. The concentrations of copper in soil samples were calculated as follow:

$\mathrm{C}=\frac{\mathrm{C}_{\mathrm{O}} \mathrm{V}}{\mathrm{m}}$

Where:

C- the concentration of copper in soil sample, $\mathrm{mg} \mathrm{kg}^{-1}$

$\mathrm{C}_{0 \text { - }}$ the copper concentration read from the calibration curve, $\mathrm{mg} \mathrm{L}^{-1}$

$\mathrm{V}$ - the total volume of solution, $\mathrm{mL}$

$\mathrm{m}$ - the weight of dried sample taken for analysis, $\mathrm{g}$

\section{RESULTS AND DISCUSSION}

The values of the copper concentrations were mathematical processed and the results are presented in Fig. 2-7.

The accuracy of the ICP-AES analysis method of soil samples was tested based on statistical parameters. The content of copper in each soil sample was analyzed twice and the statistical parameters were calculated as example presented in Table 1.

The values of statistical parameters recorded for each soil sample indicate a high precision of ICP-AES method.

A general overview of Fig. 2-4 shows that the copper' concentrations in soil samples exceed normal admitted values and in mostly cases are higher than the alert and intervention levels provided by the Romanian Standard for Heavy Metals (Table 2).

In 2001, the highest concentrations of copper were recorded in the so called "protection area" (Fig. 1-3) and they are decrease with the distance. Even we can speak about a historical pollution, caused by the geological structure ${ }^{[5]}$, two aspects can be considered main responsible by the actual high level of pollution in the area:

1. The ecological accident occurred in January 2001, when the broken wall allowed the spill of wastewaters from Transgold pond charged with high amounts of heavy metals and cyanides.

2. As the Fig. 2-4 show, the area represents the confluence of sedimentation ponds. Low level of the area, comparing with the higher levels of surrounded ponds and fields, allows the accumulation of waters which wash the walls of the ponds and dissolved important quantities of heavy metals combinations. As intensive evaporation process along of the summer, a layer of copper combinations are deposited on the surface. The fine particles from the walls of the ponds, transported by the strong winds in the area have an important contribution to increase the thickness of the solid sediment on the surface.

The porous structure of soil plays an important role in the dispersion of the pollutants. As the Fig. 3 shows the copper concentrations at $30 \mathrm{~cm}$ depth are higher than on surface $(5 \mathrm{~cm})$ but the dispersion's configuration is different. We can notice and expand of the surfaces with lower concentrations, simultaneously with the decrease of the strong polluted areas, the field with the higher concentration having the minimum area. In this area, the copper concentration is higher with $0.1 \%$, increasing from $900 \mathrm{mg} \mathrm{kg}^{-1}$ in 2001 to $1000 \mathrm{mg}$ $\mathrm{kg}^{-1}$ in 2002. Even in the lowest concentration area can be observed the increase of copper level with $0.42 \%$ (from $25 \mathrm{mg} \mathrm{kg}^{-1}$ in 2001 to $37.5 \mathrm{mg} \mathrm{kg}^{-1}$ in 2002). A possible explanation of high levels of the concentrations at $30 \mathrm{~cm}$ depth is related to the high porosity of the soil which allows the penetration not only of the surface waters but also the infiltration waters coming from the ponds located in the area. The presence of the channels in the texture of the soil assures the preferentially flow directions which conduct to a relative uniform dispersion of pollutants in the soil. Starting from the low level of rains in the area, we can conclude that the greatest influence is represented by the infiltration waters. The supposition is supported by the highest copper concentration recorded in 2001 $\left(1000 \mathrm{~m} \mathrm{~kg}^{-1}\right)$ in the maximum confluence area of the sedimentation ponds (Fig. 3).

The pollution potential of the ponds can be noticed by studying the evolution of copper concentrations levels in the samples collected in 2002 from the surface of the soil $(5 \mathrm{~cm}$ depth) at the same points as 2001. In analysis we have to consider the presence of the protection area and the channel built after the accident. As the Fig. 5 shows, the copper concentration inside of the protection area is slightly increases because of polluted waters accumulation and the solid particles transported by the winds. Concentration curves indicate the maximum copper concentration just in the origin point of A direction (Fig. 1 and 4), the value recorded in this point being $7288 \mathrm{mg} \mathrm{kg}^{-1}$ comparing with those recorded in the very next point $\left(441 \mathrm{mg} \mathrm{kg}^{-1}\right)$ and in the origin point but in $2001\left(293 \mathrm{mg} \mathrm{kg} \mathrm{kg}^{-1}\right)$. A contamination occurred along of the collecting, preservation or analyzing of soil sample collected from this point or a local accidental accumulation increased the concentration of copper. As consequence, average concentration along of $\mathrm{A}$ direction influenced the structure of the dispersion curve as presented in Fig. 4. The beyond suppositions are supported by the considered "more normal" values along of B - E directions, which are a little lower $(\mathrm{B}, \mathrm{C}$ and $\mathrm{D})$ or equal (E) with those of the previous year. The next algorithm was followed to avoid the influence of 
Table 1: Calculation of statistical parameters

\begin{tabular}{lllllll}
\hline Element & $\begin{array}{l}\text { Partial results } \\
\left(\mathrm{mg} \mathrm{kg}^{-1}\right)\end{array}$ & $\begin{array}{l}\text { Mean value } \\
\left(\mathrm{mg} \mathrm{kg}^{-1}\right)\end{array}$ & $\begin{array}{l}\text { Standard } \\
\text { deviation }(\mathrm{s})\end{array}$ & $\begin{array}{l}\text { Population } \\
\text { standard }(\mathrm{S})\end{array}$ & $\begin{array}{l}\text { Relative standard } \\
\text { deviation }(\mathrm{RSD}(\%))\end{array}$ & $\begin{array}{l}\text { Final result } \\
\left(\mathrm{mg} \mathrm{kg}^{-1}\right)\end{array}$ \\
\hline $\begin{array}{l}\mathrm{Cu} \text { at } 30 \mathrm{~cm} \\
\text { depth, } 2001\end{array}$ & 33 & 30 & 4.2 & 2.98 & 10 & $30 \pm 3$ \\
\hline
\end{tabular}

\begin{tabular}{|c|c|c|c|c|c|}
\hline \multirow[t]{2}{*}{ Element } & \multirow[t]{2}{*}{$\begin{array}{l}\text { Normal values } \\
\left(\mathrm{mg} \mathrm{kg}^{-1}\right)\end{array}$} & \multicolumn{2}{|l|}{$\begin{array}{l}\text { Alert level } \\
\left(\mathrm{mg} \mathrm{kg}^{-1}\right)\end{array}$} & \multicolumn{2}{|c|}{$\begin{array}{l}\text { Intervention level } \\
\left(\mathrm{mg} \mathrm{kg}^{-1}\right)\end{array}$} \\
\hline & & Sensitive & Less sensitive & Sensitive & Less sensitive \\
\hline $\mathrm{Cu}$ & 20 & 100 & 250 & 200 & 500 \\
\hline
\end{tabular}

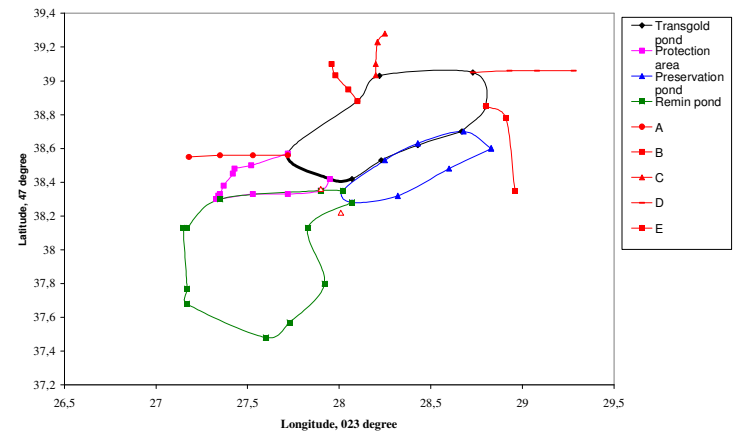

Fig. 1: Location of the sedimentation ponds and sampling points the broken wall in January 2000 ecological accident
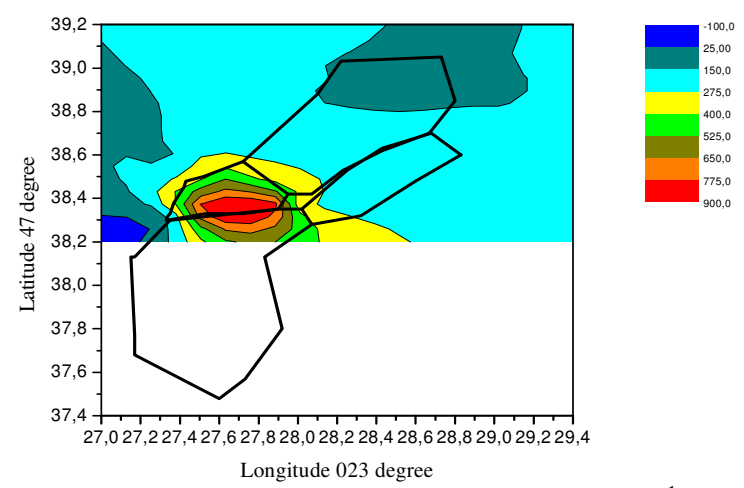

Fig. 2: Dispersion of copper concentrations $\left(\mathrm{mg} \mathrm{kg}^{-1}\right)$ in soil at $5 \mathrm{~cm}$ depth (2001) correlated with the location of sedimentation ponds
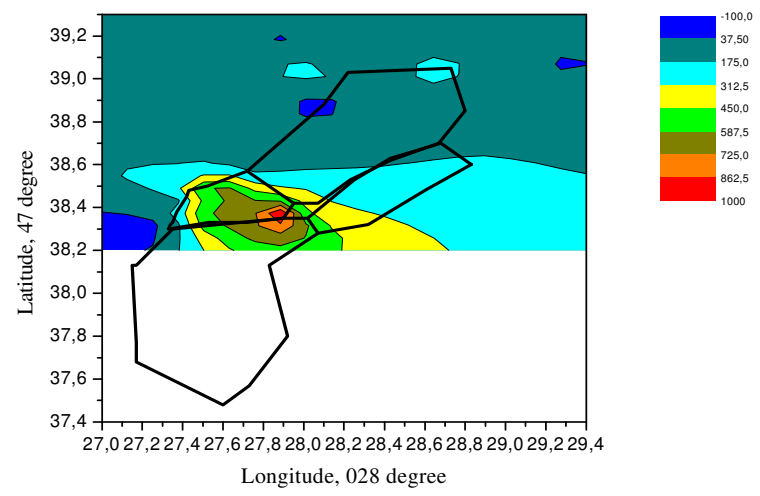

Fig. 3: Dispersion of copper concentrations (mg kg-1) dispersion in soil at $30 \mathrm{~cm}$ depth (2001) correlated with the location of sedimentation ponds
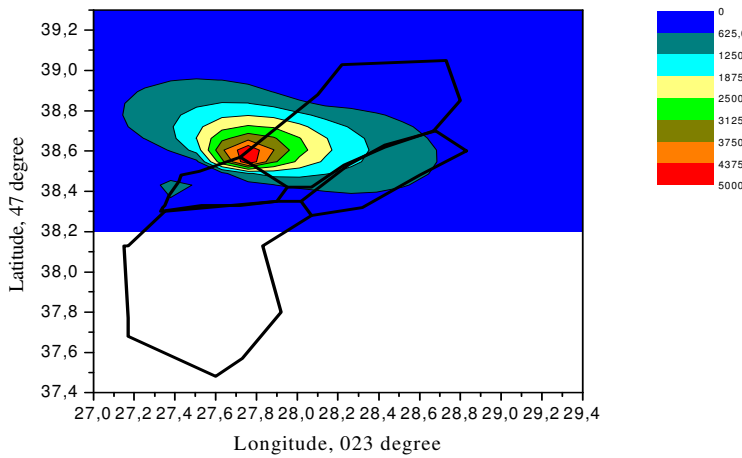

Fig. 4: Dispersion of copper concentrations $\left(\mathrm{mg} \mathrm{kg}^{-1}\right)$ in soil at $5 \mathrm{~cm}$ depth (2002) correlated with the location of sedimentation ponds

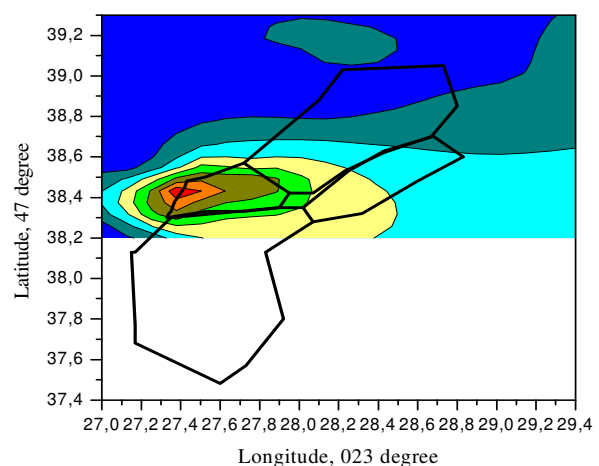

Fig. 5: Dispersion of copper concentrations $\left(\mathrm{mg} \mathrm{kg}^{-1}\right)$ in soil at $5 \mathrm{~cm}$ depth (2002) correlated with the location of sedimentation ponds

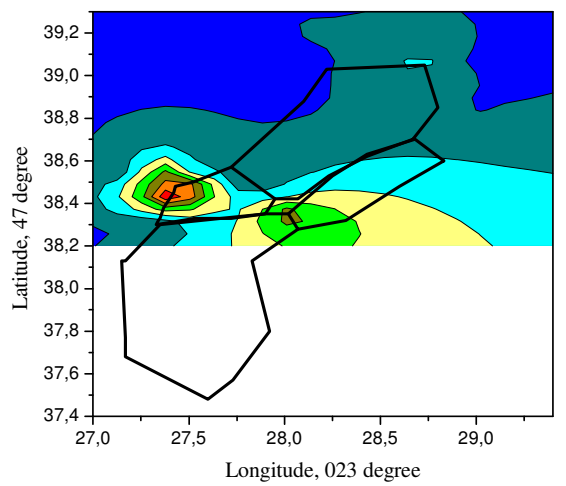

Fig. 6: Dispersion of hypothetic copper concentrations $\left(\mathrm{mg} \mathrm{kg}^{-1}\right)$ in soil at $30 \mathrm{~cm}$ depth (2002) correlated with the location of the sedimentation ponds 


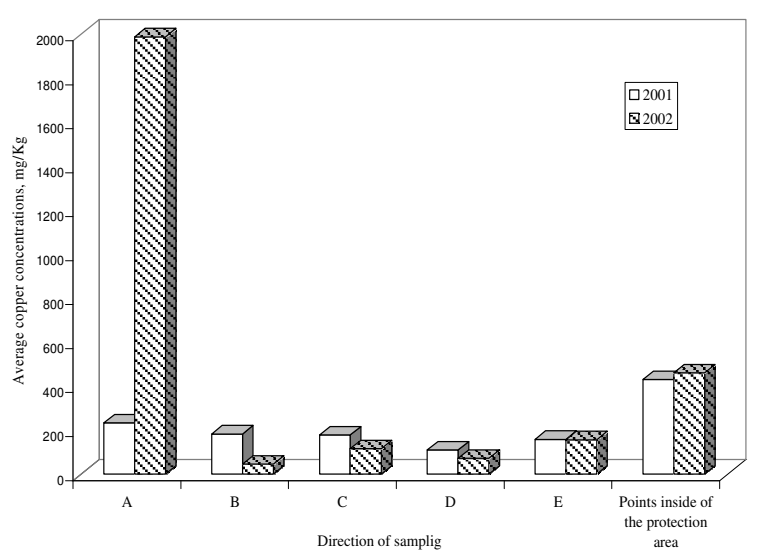

Fig. 7: Evolution in time of copper concentration in surface soil samples

non-representative value of copper concentration in the origin of A direction. We consider that in this point, the 2002 copper concentration remained at least at the same level as 2001 and we replaced the value $7288 \mathrm{mg} \mathrm{kg}^{-1}$ with $292 \mathrm{mg} \mathrm{kg}^{-1}$ in the mathematical model of dispersion. The obtained dispersion curves are presented in Fig. 5. As consequence of pollutant transport by the surface water, a decrease of the maximum concentrations areas concomitant with theirs removing to the opposite wall of those which collapsed in 2001 was observed next to the persistence of strong polluted areas at the confluence of ponds.

Thus in 2002 the soil samples wasn't collected from $30 \mathrm{~cm}$ depth, a theoretical evaluation of copper dispersion has been designed. In this end, the calculation of the ration between copper concentration at surface and copper concentration at $30 \mathrm{~cm}$ depth in 2001 was performed. Knowing the copper concentration on surface in 2002 and considering the same ration in 2002 as 2001, the 2002 hypothetic copper concentrations at $30 \mathrm{~cm}$ depth were calculated. Based on these results the distribution curves presented in Fig. 6 were obtained. The built channel represents an obstacle against copper dispersion to capillarity from Transgold pond to confluence area. The role plays by the channel is showed by the medium $\left(650 \mathrm{mg} \mathrm{kg}^{-1}\right)$ and low (350 mg kg $\mathrm{g}^{-1}$ ) concentrations areas, larger than the highest concentration areas $\left(1000 \mathrm{mg} \mathrm{kg}^{-1}\right.$, $800 \mathrm{mg} \mathrm{kg}^{-1}$ ) recorded in 2001 (Fig. 3). The areas with highest concentrations keep the orientation to the infiltration waters flow direction.

\section{CONCLUSION}

Study was develop without consider the nature of chemical combinations of copper and the presence of vegetation in the studied areas.
Next to texture and porosity of soil, some characteristics of chemical combinations, especially density and solubility, have a major influence on the dispersion of pollutant both on surface and depth. Combinations with low density (high mobility) are easily transported by the winds and dispersed on the surface and those with high water solubility contribute to increase the concentration in depth.

Many plants have a high capacity to accumulate and storage the pollutants from soil. In studied areas, the spontaneously vegetation is represented by different species of grass and burs. Starting from the fact that the study occurred in the maximum vegetation period, we can appreciate that the copper level in soil is higher than the chemical analysis of soil samples indicate.

A correct appreciation of the pollution level with copper should consider both the species of chemical combinations of copper and the amounts of copper accumulated by the plants. Even neglecting these aspects the copper level in the area can be considered very high.

\section{AKNOWLEDGEMENTS}

We would like acknowledge that the results presented in this study are part of the experimental data obtained in the frame of the project IRCYL ICA2-199910065. The research funds were provided by the European Commission and MECT-Romania. We express our thanks to our colleagues from ICIA Cluj Napoca for all the help provided.

\section{REFERRENCES}

1. Ipromin Sa, S.C., 1977. Study of stability and expertise of safety of Bozanta Pond, 67-45-2.

2. IRCYL ICA 2-1999-10065. Investigation of the risk of cyanide in the gold leaching on health and environment in Central Asia and Central Europe, Technical Annex.

3. Anonymous, 2000. Methodology for determination of the heavy metals in soil and sediment, Study protocol of ICIA Cluj Napoca, Romania.

4. Anonymous, 1997. Romanian Order No. 756/1997 of the Forests, Waters and Environment Ministry.

5. Nadisan, I. and D. Chereches, 2000. Truth About Pollution. Vasile Goldis University Press, Baia Mare, pp: 22. 